\title{
Applying system dynamics for outsourcing services in design-build projects
}

Stephen D Lisse

Virginia Polytechnic Institute and State University, Falls Church, VA, USA

\begin{abstract}
This study analysed a system dynamics model for outsourcing engineering services in a large and complex project organisational structure that is typically associated with design-build (DB) project delivery. A literature review indicated that most of the reviewed papers implied the project engineering resources were totally insourced or the authors were silent regarding any resources that were outsourced. Comprehensive sensitivity analysis of various model variables was performed, which indicates that the quality and productivity of the outsourced resources as well as the initial number of assigned experienced engineers significantly impacted the amount and timing of engineering work completion. Project outcomes were also impacted by varying the number of initial and changed engineering tasks. The decision to insource/outsource engineering work on DB projects may have significant cost and time impacts, which should be considered by decision makers.
\end{abstract}

Keywords: System dynamics, outsourcing, project management, quality, productivity, engineering, design-build

\section{Introduction}

The ability of owners and managers to execute design-build (DB) projects is dependent upon implementing best practices that realise affordability and cost management. It is becoming increasingly imperative to provide quality DB services within existing and projected budgetary and time constraints.

Outsourcing services on DB projects may only produce short-term profitability and may have negative impacts upon the project and organisational sustainability. By insourcing engineering and construction services, the project organisational core competencies are increased leading to long-term financial and operational sustainability of the DB project.

By using system dynamics (SD), the performance of engineering and construction services can be expressed as a feedback model that can enable project management to understand how an engineering or construction problem developed over time, and assist in finding a lasting solution to the problem. The system dynamic approach incorporates subjective factors that have important influences on the whole project.

Accordingly, the SD model will enable managers to prudently decide what, if any, project services to outsource in order to satisfy the project financial and time requirements. 


\section{Literature review}

Earlier, Huot and Cooper (1982) discussed SD to model large projects strategy management by three primary components. Those components are the state of the system, the rates of change, and the information networks. In a series of causal loops, the impacts of construction productivity to engineering productivity were linked to give project management decision makers a dynamic tool to access project schedule outcomes. Accordingly, construction problems can form reinforcing loops and become larger project problems.

Rodrigues and Bowers (1996) later developed an SD model of the human resource management cycle to analyse the project control cycle. This study analysed the impact upon project duration of the following three parameters: the productivity, the number of staff working, and the work rate. However, a detailed schedule and traditional network analysis was also needed for project control, and it is assumed that all resources in this study were insourced.

Then Alfeld et al. (1998) studied the dynamic complexities of the ship construction process and developed a simulation model of the planning and replanning process. It captured both the essential physical shipbuilding and the essential management decision making that support the physical production processes. In this model, two submodels interacted to calculate the specific allocation of resources over time necessary to produce the ship, and there was no indication whether these resources were in-house or subcontracted (outsourced).

Also, Love et al. (2002) described how changes impact project performance using system dynamic methodology. The two basic sources of dynamics that infringe upon a project system include planned activities with attended dynamics-factors resulting from active interventions, and uncertainties with unattended dynamics-factors beyond the control of project management. Findings from this case study indicated that 50 per cent of the rework costs resulted from poor motivation levels of the architects and engineers with no differentiation between insourced and outsourced staff.

Park (2005) proposed a model-based dynamic approach for construction resource (labour and material) management. The model simulation of the resource level targeting process indicated there is a time-cost tradeoff of resource coverage and project performance. Also, policy implications were discussed for the key variables, listed as the target material level, the target workforce level, the material acquisition rate and the workforce based engineering rate, without mention of any outsourcing.

Closely following the above, Lee et al. (2006) introduced the system's perspective of dynamic planning and control methodology to support the strategic and operational aspects of project management. The integration of the traditional critical path method approach and SD modelling by Vensim was developed into a project management tool whose characteristics included a strategic core of SD, a tactical layer of agent-based modelling, an operational layer of networkbased tools, optimisation techniques, discrete-event simulation and statistics, and an interface layer with Gantt chart, dependency structure matrix, smart cell, behavioural graph and 4D visualisation. Again, there was no indication that the staffing was insourced or outsourced in the study. 
Minami et al. (2010) used SD methodology to model the engineering process and conducted simulations to examine the impact of project management decisions. They concluded that increased constructability efforts and design sharing mitigated the impact of cost overruns and project completion delays. Also, the study concluded that it is best to focus improvement efforts early in the project when limited resources exist and insourcing/outsourcing of resources was not discussed.

Recently, Han et al. (2012) developed an SD model to capture the dynamics of design errors and systematically assess their negative impacts. Rework due to design errors and design changes are considered to be the primary contributor to schedule delay and cost overruns in DB projects. The research indicated that, despite the continuous schedule recovery efforts by project managers, design errors could significantly delay the project schedule. Further, it is shown that schedule pressure can propagate negative impacts to various construction activities not associated with the design errors. The outsourcing of design staff was also not discussed.

Lisse (2012a) developed a preliminary SD model of the outsourcing of construction services in large shipbuilding projects, which are comparable to DB projects. Vensim software was used and the most productive use of total construction effort was shown to be $20 \%-90 \%$ outsourced for the project parameters used.

Subsequently, Lisse (2012b) developed an SD model for determining the outcome for outsourcing engineering services in the large and complex project organisational structure that is typically associated with DB project delivery. The results of running this Vensim model indicated that the amount and timing of engineering task work completed depended upon both the productivity and quality of the outsourced engineering services as well as the initial number of experienced engineers. This SD model was validated, and compared well with actual data from a $\$ 3$ billion DB transit project. The model contains 398 causal loops and is shown as Figure 1 , and the model variables are listed in the Appendix. 


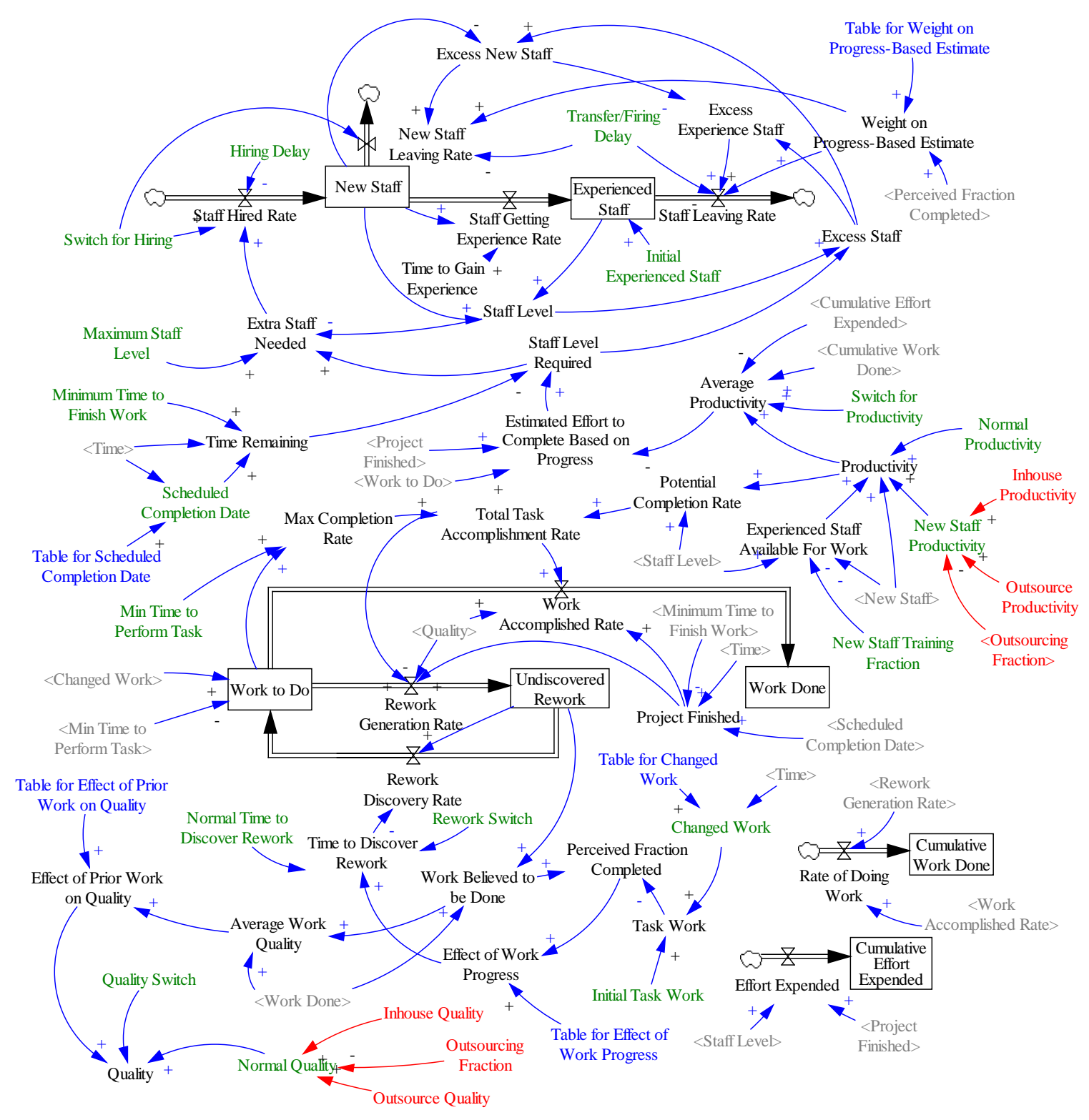

Figure 1. SD model for outsourcing engineering services in a DB project, Lisse (2012b)

The DB model variables used in the SD model for the current study included the following:

- Initial scheduled completion date: 60 days

- Revised scheduled completion date: 70 days

- Changed work scope at: Day 50

- Initial experienced staff: 3 people

- Maximum staffing: 10 people

- Initial engineering work: 60 tasks

- Added engineering work: 10 tasks 


\section{Results and discussion}

This literature review indicates that the success of a project depends upon the productivity and quality of the staff as well as the initial number of experienced staff providing those services. Additionally, all workers new to the DB project exhibit a learning curve while accommodating to the project organisation and culture. However, the vast majority of reviewed papers indicated the additional resources provided were totally insourced or the authors were silent regarding any resources that were outsourced. Thus, one would have to assume that those reviewed studies involved insourced engineering and construction resources.

The present study performs an extended analysis of the impacts of quality and productivity of $100 \%$ outsourced engineering services as well as the initial number of experienced engineers upon the engineering task outcome of the DB project using the previously validated SD model.

The results of running the SD model with varying outsourced quality from 0.8 to 1 (80-100\% based upon a normal value of 1) to determine the effect upon the engineering work output is shown in Figure 2. For the variables used in this study, it indicates that the $100 \%$ Quality case always presents the largest engineering task completion during any period during the project duration. It is also shown that, except in the $100 \%$ Quality case, the outsourced engineering work completion date extends beyond the revised project scheduled completion date (Day 70). This is caused by the associated learning curves of the outsourced engineers. This also implies that management should concentrate on providing the highest quality engineering resources through the project completion.

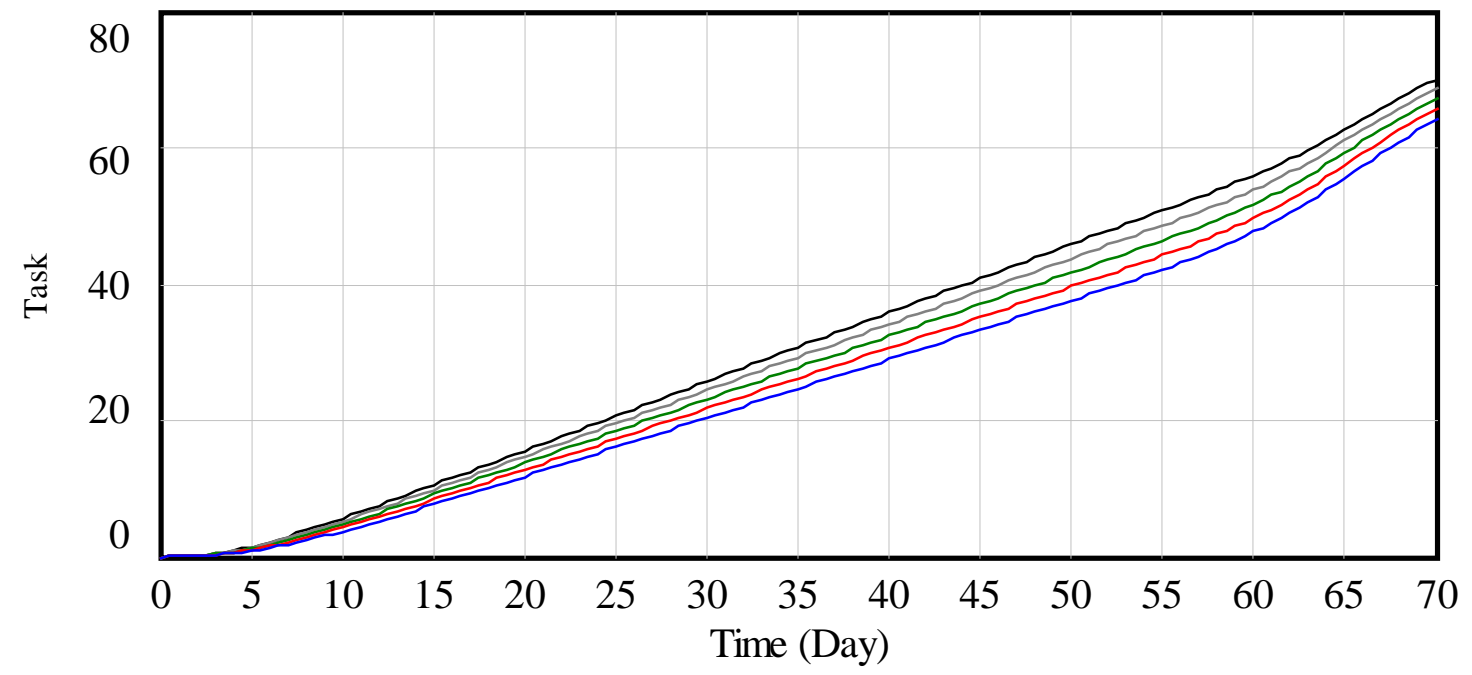

Work Done : 100\% Outsourcing Quality 80\% Work Done : 100\% Outsourcing Quality 85\% Work Done : 100\% Outsourcing Quality 90\% Work Done : 100\% Outs ourcing Quality 95\% Work Done : 100\% Outsourcing Quality 100\%

Figure 2. Work completed per quality of outsourced services 
The staff level required by the project in order to accomplish the initial and changed engineering tasks is shown in Figure 3. Again, the outsourced quality was varied from 0.8 to 1 ( $80-100 \%$ based upon a normal value of 1 ). This indicates that the $100 \%$ Quality case required less engineering staffing in order to complete the assigned tasks at the original and revised scheduled project completion dates. This case was actually reducing staffing as the assigned work approached the original completion date. It also shows that all cases were disrupted by the added engineering work at Day 50 and used more equivalent engineers than the planned maximum of 10 to complete the remaining engineering tasking during the extended project duration. Besides adding new engineers, overtime and weekend work could be used to meet the new requirements.

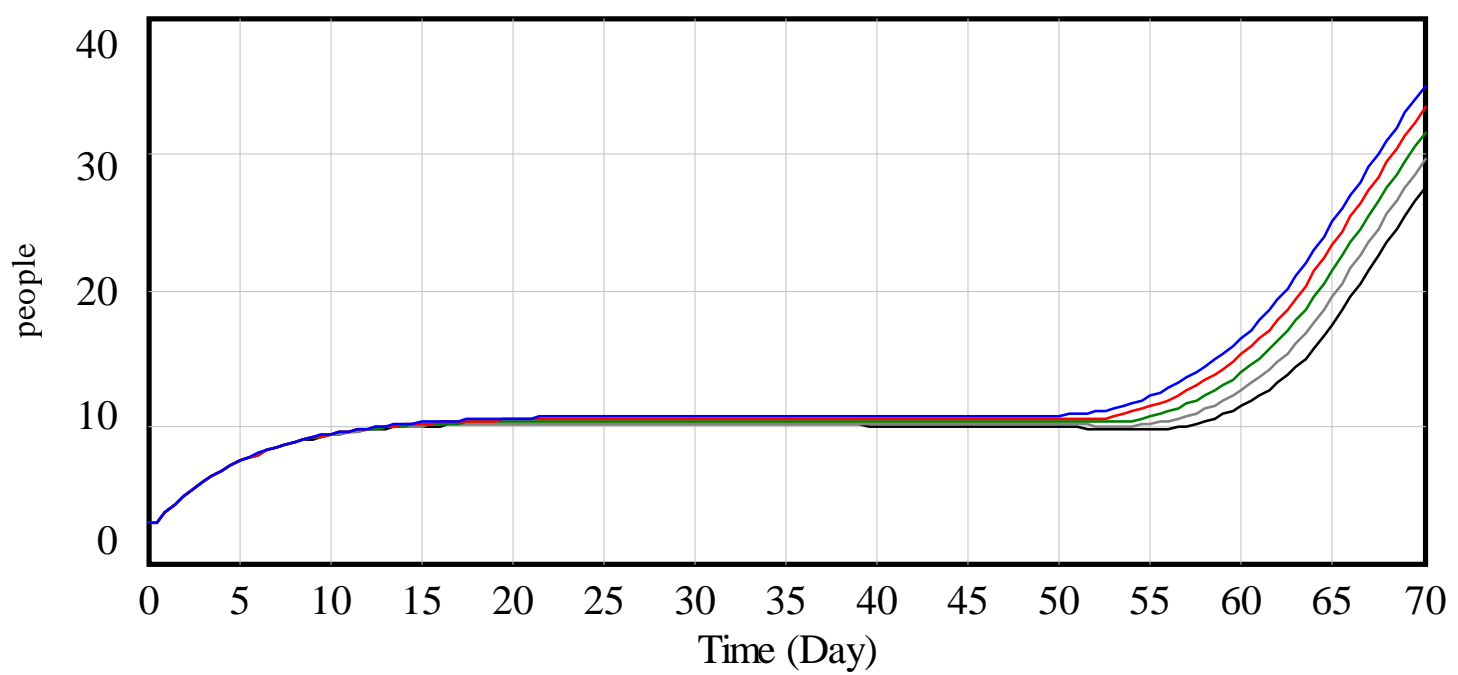

Staff Level : 100\% Outsourcing Quality 80\% Staff Level : 100\% Outsourcing Quality 85\% Staff Level : 100\% Outsourcing Quality 90\% Staff Level : 100\% Outsourcing Quality 95\% Staff Level : 100\% Outsourcing Quality 100\%

Figure 3. Staff level per quality of outsourced services

Likewise, when varying outsourced productivity, the staff level required by the DB project in order to accomplish the initial and changed engineering tasks is shown in Figure 4. The outsourced productivity was varied from 0.05 to 0.1 task/(people*day) (50-100\% based upon a normal value of 0.1 ). This indicates that the $100 \%$ Productivity case required less overall engineering staffing in order to complete the assigned tasks during the project duration.

Also, as Figure 5 indicates, most outsourced productivity cases approached the normal average productivity value of 0.1 . However, the three lowest engineering productivity cases were not able to reach the normal value of 0.1 during the project duration. Thus, these cases need larger engineering staffing over most of the project duration. 


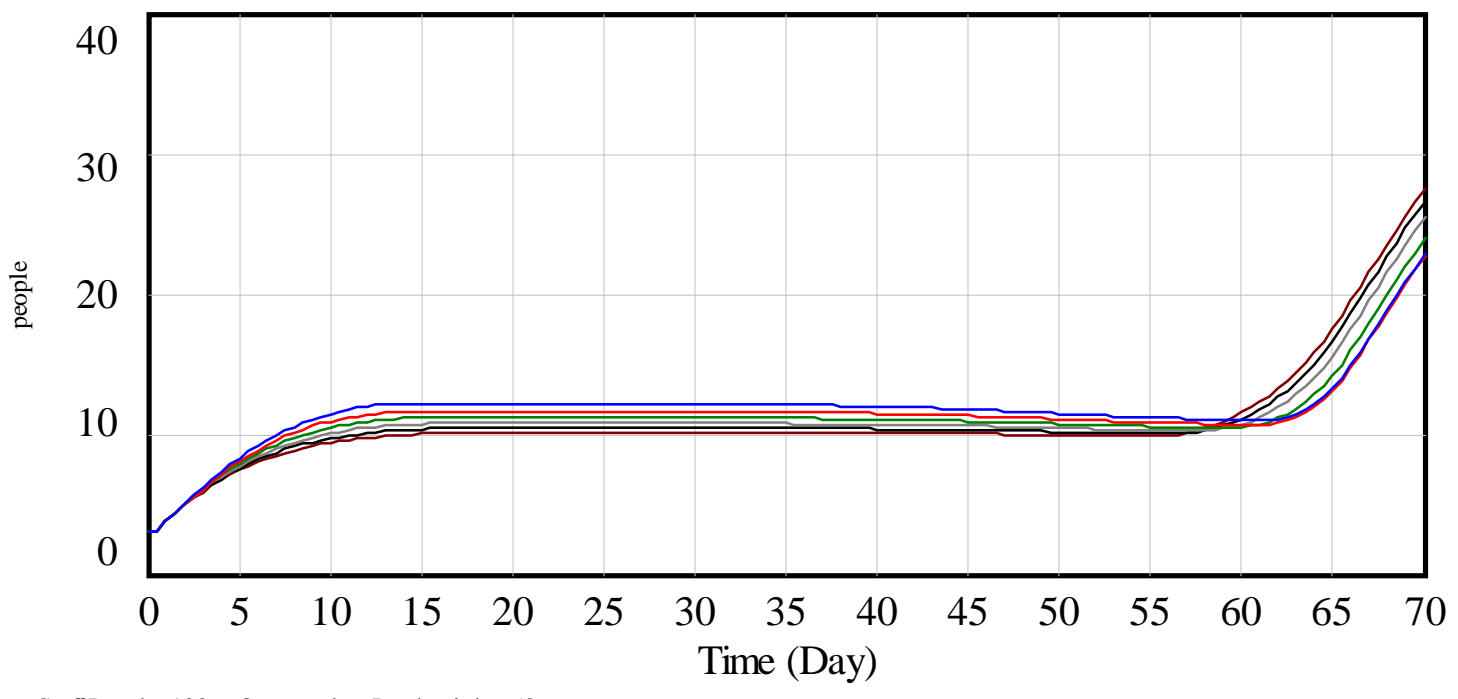

Staff Level : 100\% Outsourcing Productivity 50\%

Staff Level : 100\% Outsourcing Productivity 60\%

Staff Level : 100\% Outsourcing Productivity 70\%

Staff Level : 100\% Outsourcing Productivity $80 \%$

Staff Level : 100\% Outsourcing Productivity 90\%

Staff Level : 100\% Outsourcing Productivity 100\%

Figure 4. Staff level per productivity of outsourced services

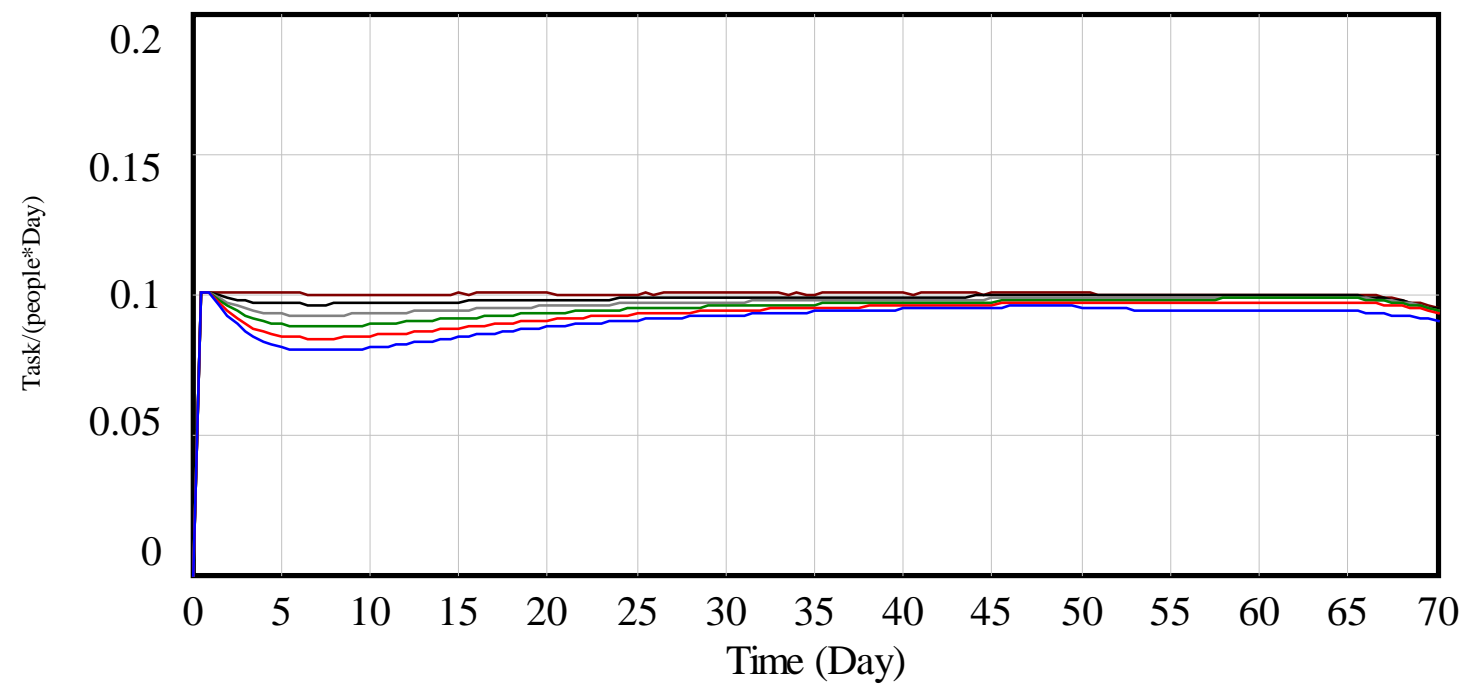

Average Productivity : 100\% Outsourcing Productivity 50\%

Average Productivity : 100\% Outsourcing Productivity 60\%

Average Productivity : 100\% Outsourcing Productivity 70\%

Average Productivity : 100\% Outsourcing Productivity 80\%

Average Productivity : 100\% Outsourcing Productivity 90\%

Average Productivity : 100\% Outsourcing Productivity 100\%

Figure 5. Average productivity per productivity of outsourced services 
This leads to the larger engineering staff required at the lower productivity cases actually completing more engineering tasks after Day 20 than the 100\% Productivity case as shown in Figure 6. Those larger staffs benefitted most from the learning curve, since the lower productivity cases actually had substantial average productivity gains over the project duration. Therefore, the larger numbers of engineers are able to overall complete more tasks, but at a very significant added cost to the DB project.

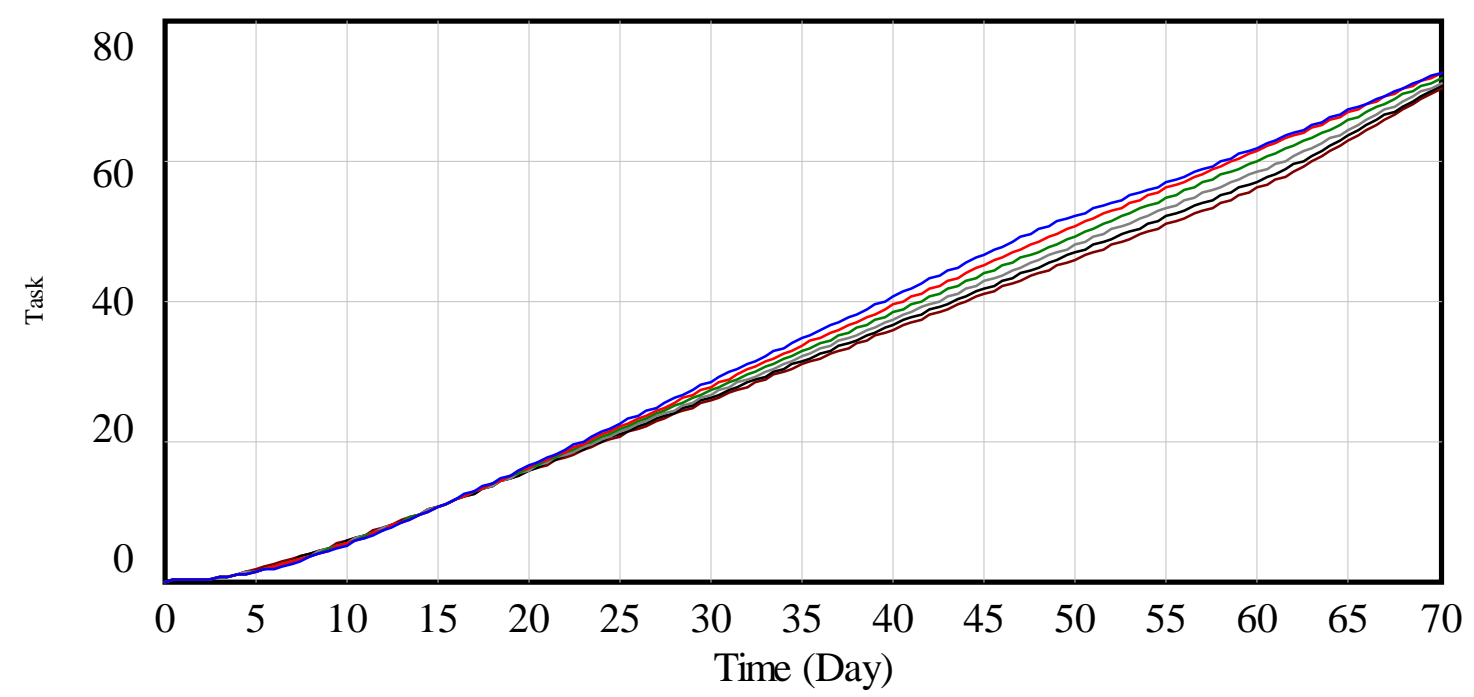

Work Done : 100\% Outsourcing Productivity 50\%

Work Done : 100\% Outsourcing Productivity 60\%

Work Done : 100\% Outsourcing Productivity 70\%

Work Done : $100 \%$ Outsourcing Productivity $80 \%$

Work Done : 100\% Outsourcing Productivity 90\%

Work Done : 100\% Outsourcing Productivity 100\%

Figure 6. Work completed per productivity of outsourced services

Additionally, the impact of the number of initial experienced staff upon the DB project was analysed in the SD model. That variable was varied from 2 to 12 engineers (the SD model norm was 3), and the estimated effort to complete the 70 engineering tasks is shown in Figure 7. The quality and productivity of outsourced engineers were assigned as 1 and 0.1 , respectively. It is indicated that 2-10 initial experienced engineers had similar estimated effort to complete the engineering work by the extended project completion date. Also, it is shown that the 12 Initial Experienced Staff case provides the least overall estimated effort to complete the assigned engineering tasks by the revised scheduled project completion date if those resources were available and within the project budget. Although not readily evident in the figure, all cases rapidly drop off to zero by the end of Day 70 . This is verified by viewing the variable listed in the Appendix for Estimated Effort to Complete Based on Progress. 


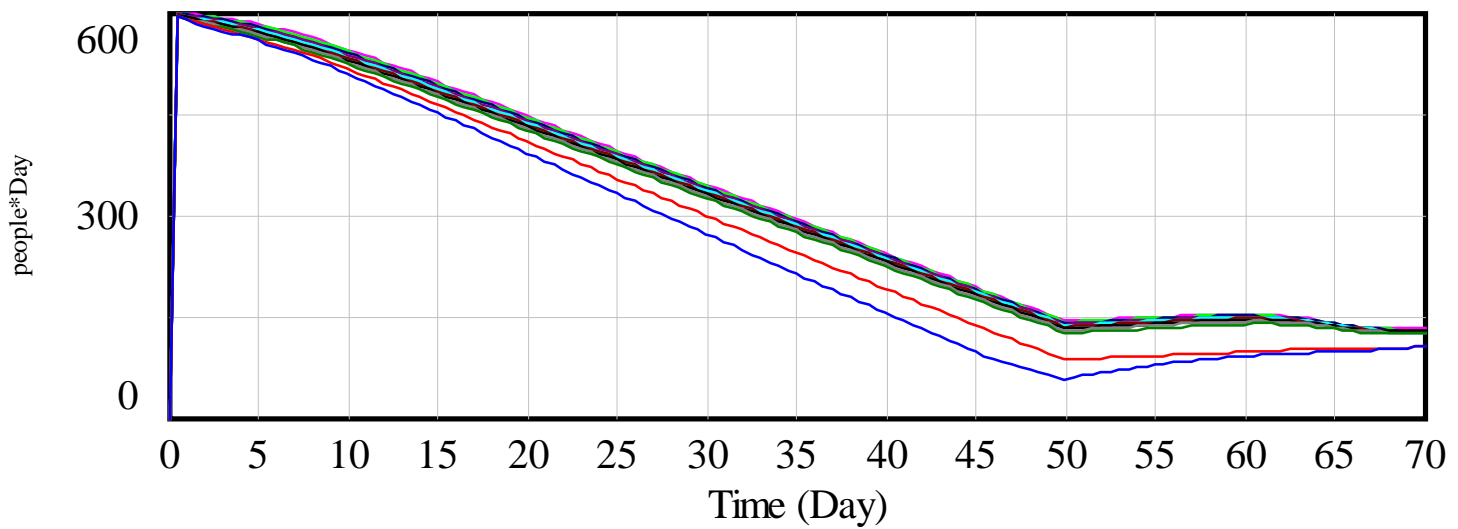

Estimated Effort to Complete Based on Progress : 100\% Outsourcing 12 Initial Experienced Staff Estimated Effort to Complete Based on Progress : 100\% Outsourcing 11 Initial Experienced Staff Estimated Effort to Complete Based on Progress : 100\% Outsourcing 10 Initial Experienced Staff Estimated Effort to Complete Based on Progress : 100\% Outsourcing 09 Initial Experienced Staff Estimated Effort to Complete Based on Progress : 100\% Outsourcing 08 Initial Experienced Staff Estimated Effort to Complete Based on Progress : 100\% Outsourcing 07 Initial Experienced Staff Estimated Effort to Complete Based on Progress : 100\% Outsourcing 06 Initial Experienced Staff Estimated Effort to Complete Based on Progress : 100\% Outsourcing 05 Initial Experienced Staff Estimated Effort to Complete Based on Progress : 100\% Outsourcing 04 Initial Experienced Staff Estimated Effort to Complete Based on Progress : 100\% Outsourcing 03 Initial Experienced Staff

Estimated Effort to Complete Based on Progress : 100\% Outsourcing 02 Initial Experienced Staff

\section{Figure 7. Estimated effort to complete per initial experienced staff}

The engineering work completed for varying numbers of initial experienced staff is shown in Figure 8. Again, the initial experienced staff was varied from 2 to 12 engineers. The 2-10 Initial Experienced Staff cases similarly complete the assigned work at the extended project completion date. It also indicates that the 11 and 12 Initial Experience Staff cases would complete the 70 assigned engineering tasks prior to the revised scheduled project completion date (Day 70).

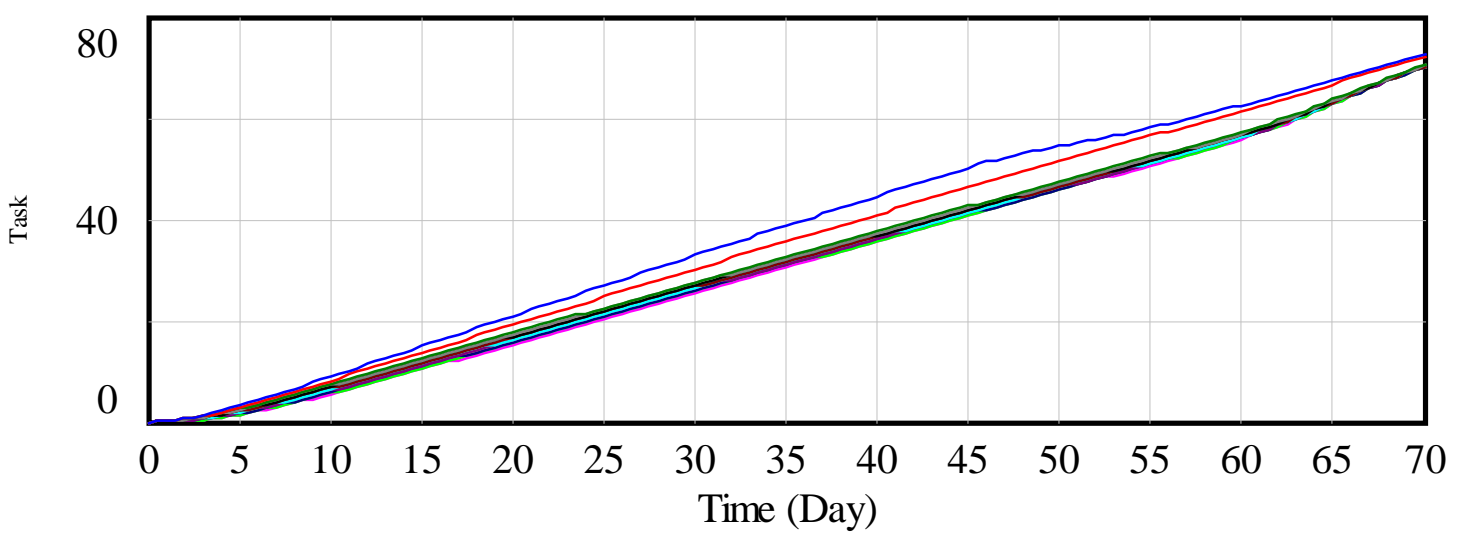

Work Done : 100\% Outsourcing 12 Initial Experienced Staff Work Done : 100\% Outsourcing 11 Initial Experienced Staff Work Done : 100\% Outsourcing 10 Initial Experienced Staff Work Done : 100\% Outsourcing 09 Initial Experienced Staff Work Done : 100\% Outsourcing 08 Initial Experienced Staff Work Done : 100\% Outsourcing 07 Initial Experienced Staff Work Done : 100\% Outsourcing 06 Initial Experienced Staff Work Done : 100\% Outsourcing 05 Initial Experienced Staff Work Done : 100\% Outsourcing 04 Initial Experienced Staff Work Done : 100\% Outsourcing 03 Initial Experienced Staff Work Done : 100\% Outsourcing 02 Initial Experienced Staff

Figure 8. Work completed per initial experienced staff 
Next, the initial and changed task work was varied to analyse the resulting outcomes for the DB project. In this study, the initial engineering task work was varied from 40-80 tasks (the SD model norm was 60 tasks), and the changed task work was held constant at 10 tasks. The resulting staff level is shown in Figure 9, and the staffing level increases with increased initial work tasks when the initial and revised project scheduled completion dates are not changed.

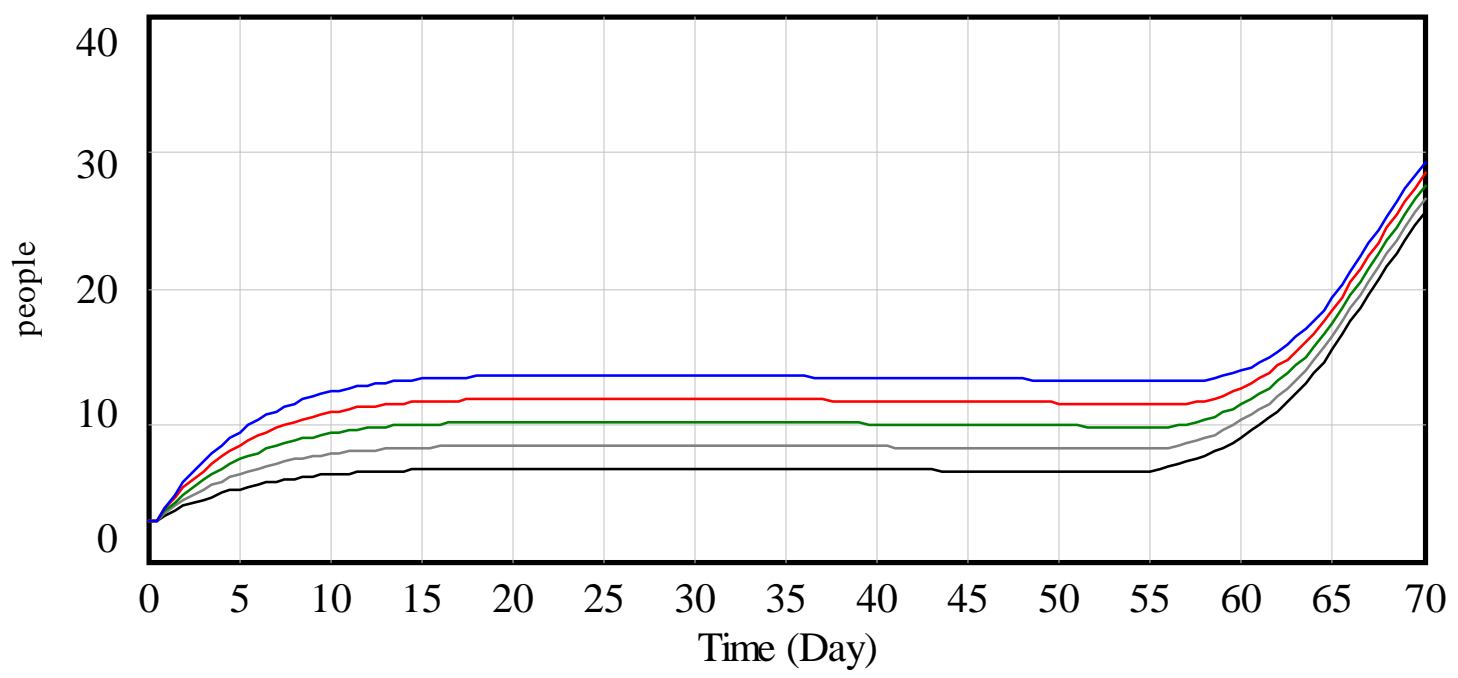

Staff Level : 100\% Outsourcing Initial Tasks 80 Staff Level : 100\% Outsourcing Initial Tasks 70 Staff Level : 100\% Outsourcing Initial Tasks 60 Staff Level : 100\% Outs ourcing Initial Tasks 50 Staff Level : 100\% Outsourcing Initial Tasks 40

\section{Figure 9. Staff level per initial task work}

In Figure 10, the initial engineering task work was again varied from 40-80 tasks (and changed work was 10 tasks), and the resulting completed task work is shown. This indicates that engineering resources associated with the varying initial task work variable are adequate to complete the engineering work within the revised scheduled project completion date. 


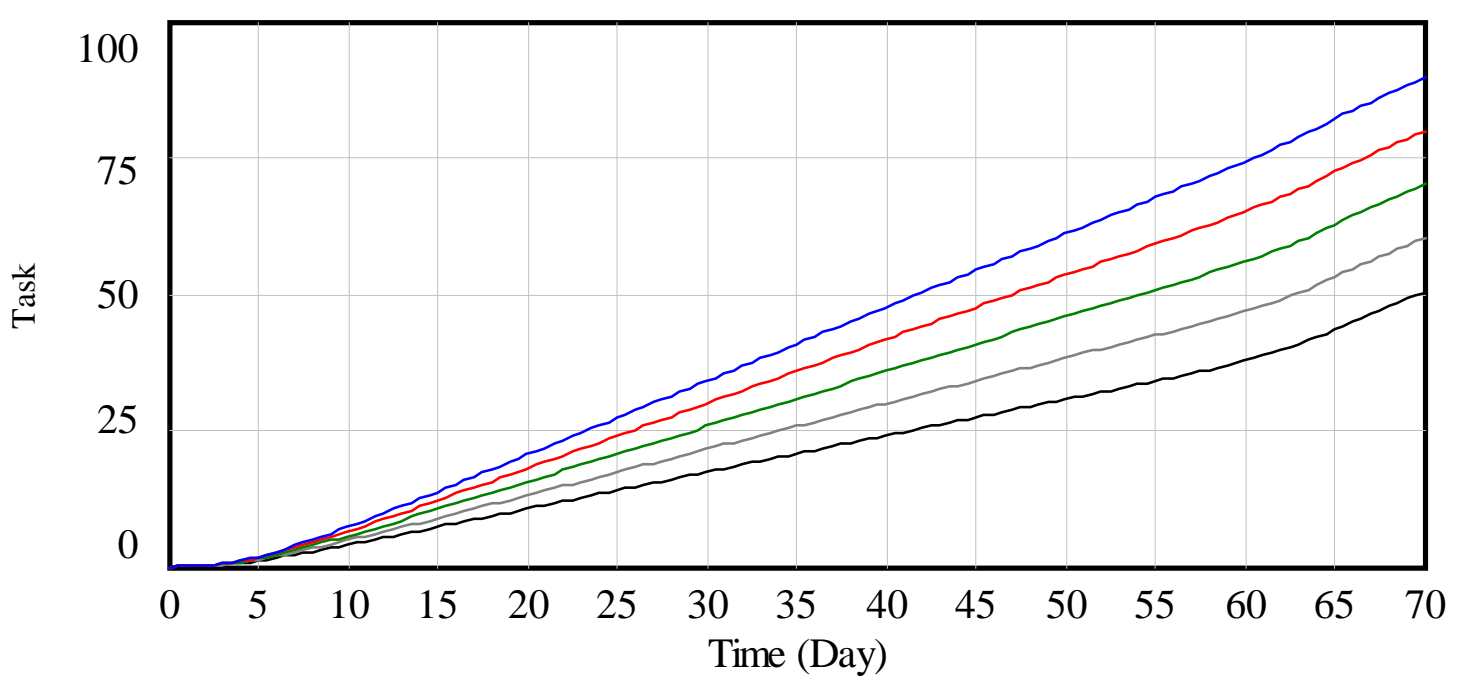

Work Done : 100\% Outsourcing Initial Tasks 80 Work Done : $100 \%$ Outs ourcing Initial Tasks 70

Work Done : $100 \%$ Outsourcing Initial Tasks 60

Work Done : $100 \%$ Outs ourcing Initial Tasks 50

Work Done : 100\% Outsourcing Initial Tasks 40

\section{Figure 10. Work completed per initial task work}

Finally, the changed task work was varied from 5-15 tasks (the norm was 10 tasks in the SD model) while keeping the initial task work constant at 60 tasks. The resulting staff level is shown in Figure 11, and the staffing level increases with increased changed work tasks when the initial and revised project scheduled completion dates are not changed.

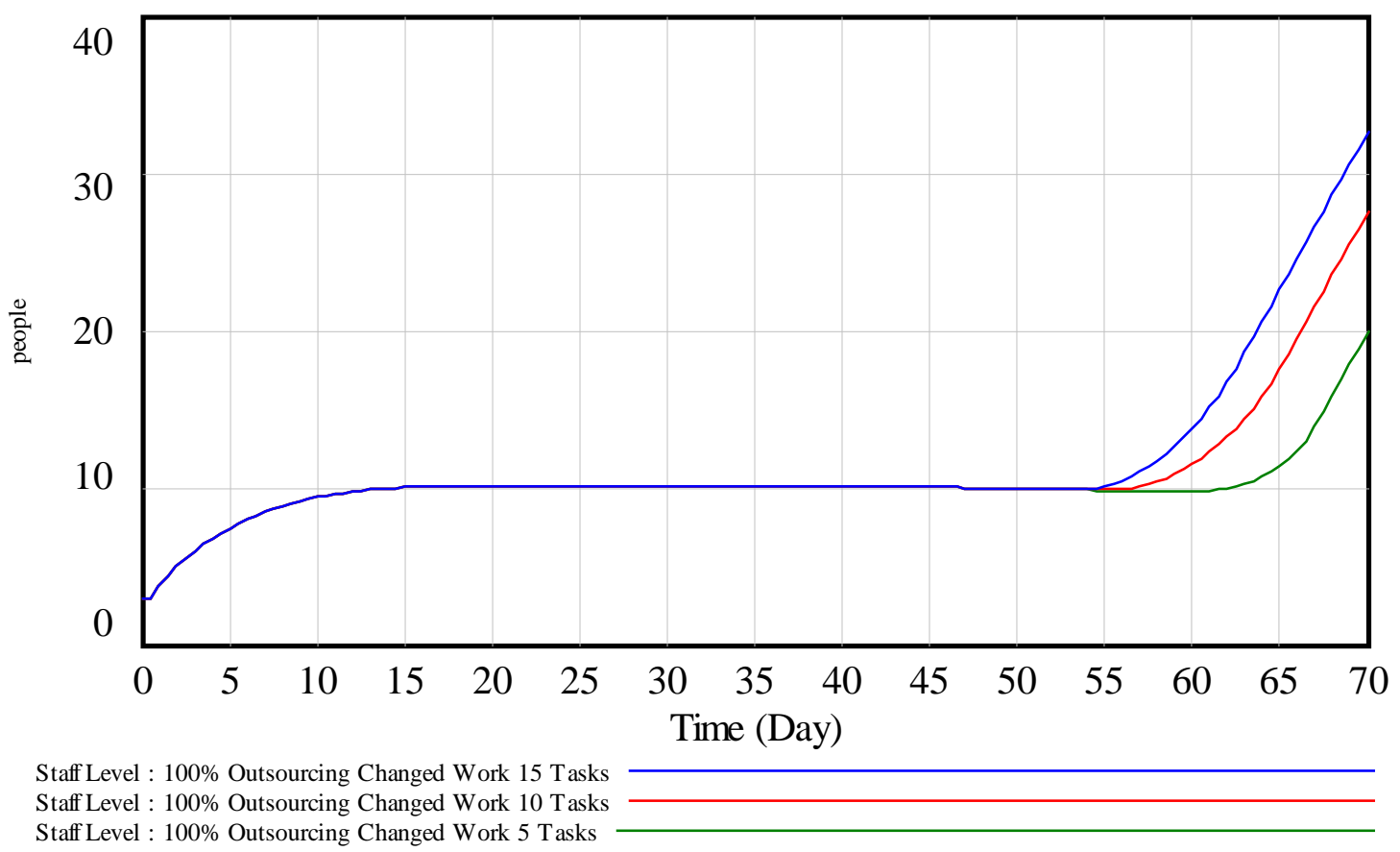

Figure 11. Staff level per changed task work 
The changed engineering task work was again varied from 5-15 tasks (and initial task work was 60 tasks), and the resulting completed task work is shown in Figure 12. This also indicates that engineering resources (10 people) associated with the varying changed task work may not be sufficient to complete the engineering work within the revised scheduled project completion date without working extensive overtime.

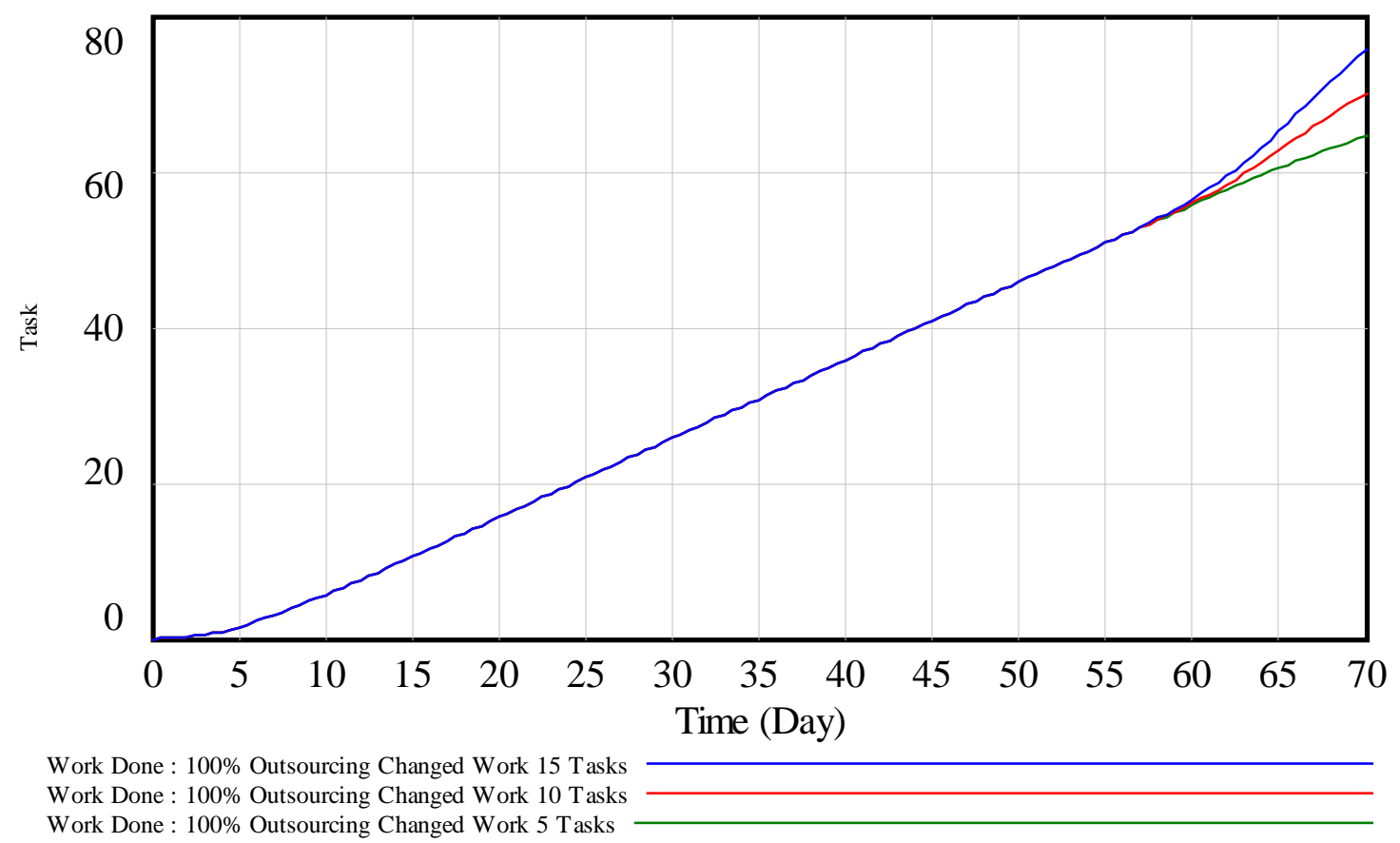

Figure 12. Work completed per changed task work

\section{SD model validation}

As mentioned, the SD model was previously tested by Lisse (2012b) to understand its limitations and to improve it. Some model tests that were performed are summarised below.

Face validity

Face validity is usually an iterative process that compares the causal loop, and stock and flow diagrams with the real-world system that is modelled. A qualitative decision was made as to the accuracy with which the SD model portrays the actual system under study. The SD model accurately describes the cost-estimating services in a DB project, including instances of changed/additional work and changed scheduled completion dates.

\section{Structure assessment tests}

Partial model tests were conducted of the decision rules and strategy rationale. Policy structure diagrams, causal loop, and stock and flow diagrams were inspected, as well as model equations to verify relevant descriptive knowledge of the system.

\section{Dimensional consistency tests}

Each equation was inspected for dimensional consistency and suspect parameters were modified. Use of parameters with no real-world meaning was avoided. 
Integration error tests

The SD model was not sensitive to the choice of time step or integration method in the Vensim software expected used for the modelling.

Extreme conditions tests

The model made sense even when its inputs took on extreme values, including policies, shocks, and parameters. The model results were inspected when responding to extreme values of each input, by itself or in combination. These tests verified model conformance to basic physical laws.

\section{Behaviour reproduction tests}

The SD model reproduced both the quantitative and qualitative behaviour of interest in the system. Statistical measures of correspondence between the model and data were computed by running the model and comparing results for a sample of $8 \mathrm{DB}$ cost estimates. The standard deviation was 0.707 days with duration variances ranging from $2.564 \%$ to $-7.692 \%$ with a mean of $-1.407 \%$, which is adequate.

Model output and data were also compared qualitatively for modes of behaviour, shape of variables, asymmetries, relative amplitudes and phasing, and unusual events.

\section{Sensitivity analysis}

The robustness of the model to the uncertainty in the research assumptions was analysed, including numerical, behavioural, and policy sensitivity. Analytic methods were used to determine the best parameters and policies. Optimisation methods were not necessary due to satisfactory estimated results. Parameter combinations that generated implausible results or reverse policy outcomes were eliminated.

\section{System improvement tests}

The impact of the modelling process on the mental models, behaviour, and outcomes for the enterprise was assessed. Modifications to the model were previously made to make the system perform better under changed/added work and changed scheduled completion dates, which reflected the project's operations.

\section{Conclusions}

There is a paucity of available literature on insourcing versus outsourcing engineering services on DB projects. Performing sensitivity analysis of the SD model indicates that the quality and productivity of the outsourced resources and the initial number of assigned experienced engineers significantly impacted the amount and timing of engineering work completion. Additionally, project outcomes were also impacted by varying the number of initial and changed engineering tasks during the project.

Accordingly, the decision to insource/outsource engineering work on DB projects may have significant cost and time impacts which should be considered by decision makers. 


\section{References}

Alfeld, L.E., Pilliod, C.S. \& Wilkins Jr., J.R. 1998, Virtual shipyard: a simulation model of the shipbuilding process, Journal of Ship Production, vol. 14, 33-40.

Han, S., Love, P. \& Pena-Mora, F. 2012, A system dynamics model for assessing the impacts of design errors in construction projects, Mathematical and Computer Modelling, In Press, DOI:10.1016/j.mcm.2011.06.039.

Huot, J.C. \& Cooper, K.G., 1982, Large project dynamics, 1982 AACE Transactions, T-1, AACE International, Morgantown, WV.

Lee, S.H., Pena-Mora, F. and Park, M. 2006, Dynamic planning and control methodology for strategic and operational engineering project management, Automation in Engineering, vol. 15, 84-97.

Lisse, S.D. 2012a, System dynamics of outsourcing construction in shipbuilding projects, Proceedings of American Society of Naval Engineers Day 2012 Symposium, Arlington, Virginia, February 2012.

Lisse, S.D. 2012b, System dynamics applied to outsourcing engineering services in design-build projects, Construction Management Association of America CM-eJournal, October, 2012, http://cmaanet.org/cmejournal.

Love, P., Holt, G., Shen, L., Li, H. \& Irani, Z. 2002, Using systems dynamics to better understand change and rework in engineering project management systems, International Journal of Project Management, vol. 20, no. 6, 425-436.

Minami, N.A, Soto, L.L. \& Rhodes, D.H. 2010, Dynamic lean management of the naval engineering process, Engineering Management Journal, vol. 22, no. 2, 36-43.

Park, M. 2005, Model-based dynamic resource management for engineering projects, Automation in Engineering, vol. 14, 585-598.

Rodrigues, A. \& Bowers, J. 1996, The role of system dynamics in project management, International Journal of Project Management, vol. 14, no. 4, 213-220.

\section{About the author}

Stephen D Lisse, P.E. is currently a PhD Student in the Department of Industrial and Systems Engineering at Virginia Polytechnic Institute and State University and is a retired US Navy Civil Engineer Corps Officer with forty years of international project/program management experience.

Email: slisse2@vt.edu

\section{Appendix}

\section{SD Model Variables}

(01) Average Productivity=Switch for Productivity * ZIDZ( Cumulative Work Done, Cumulative Effort Expended)

$+(1-$ Switch for Productivity) * Productivity

Units: Task/(people*Day)

(02) Average Work Quality=MIN(1,ZIDZ( Work Done, Work Believed to be Done))

Units: Dmnl

(03) Changed Work=Table for Changed Work(Time)

Units: Task

(04) Cumulative Effort Expended= INTEG (Effort Expended,0)

Units: people*Day

(05) Cumulative Work Done= INTEG (Rate of Doing Work,0)

Units: Task

(06) Effect of Prior Work on Quality=Table for Effect of Prior Work on Quality(Average Work Quality)

Units: Dmnl

(07) Effect of Work Progress=Table for Effect of Work Progress(Perceived Fraction Completed)

Units: Dmnl

(08) Effort Expended=IF THEN ELSE(Project Finished, 0, Staff Level)

Units: people

(09) Estimated Effort to Complete Based on Progress=IF THEN ELSE(Project Finished, 0, ZIDZ( Work to Do, Average Productivity))

Units: people*Day

(10) Excess Experience Staff=MAX(0, Excess Staff-Excess New Staff)

Units: people 
(11) Excess New Staff=MAX(0, Excess Staff-New Staff )

Units: people

(12) Excess Staff= MAX(0, Staff Level-Staff Level Required )

Units: people

(13) Experienced Staff= INTEG (Staff Getting Experience Rate-Staff Leaving Rate, Initial Experienced Staff)

Units: people

(14) Experienced Staff Available For Work=Staff Level-New Staff-New Staff Training Fraction* New Staff

Units: people

(15) Extra Staff Needed=MIN(Maximum Staff Level, MAX(0, Staff Level Required-Staff Level ))

Units: people

(16) FINAL TIME $=70$

Units: Day

(17) Hiring Delay= 5

Units: Day

(18) Inhouse Productivity $=0.06$

Units: Dmnl

(19) Inhouse Quality=0.9

Units: Dmnl

(20) Initial Experienced Staff $=3$

Units: people

(21) Initial Task Work $=60$

Units: Task

(22) INITIAL TIME $=0$

Units: Day

(23) Max Completion Rate=Work to Do/Min Time to Perform Task

Units: Task/Day

(24) Maximum Staff Level=10

Units: people

(25) Min Time to Perform Task=10

Units: Day

(26) Minimum Time to Finish Work=5

Units: Day

(27) New Staff= INTEG (Staff Hired Rate-New Staff Leaving Rate-Staff Getting Experience Rate,0)

Units: people

(28) New Staff Leaving Rate="Weight on Progress-Based Estimate"*Excess New Staff* "Transfer/Firing

Delay"*Switch for Hiring

Units: people/Day

(29) New Staff Productivity=Inhouse Productivity*(1-Outsourcing Fraction)+Outsourced Productivity*Outsourcing

Fraction

Units: Dmnl

(30) New Staff Training Fraction= 0.25

Units: Dmnl

(31) Normal Productivity $=0.1$

Units: Task/(Day*people)

(32) Normal Quality=Inhouse Quality*(1-Outsourcing Fraction) + Outsource Quality* Outsourcing Fraction

Units: Dmnl

(33) Normal Time to Discover Rework=3

Units: Day

(34) Outsource Productivity=0.1

Units: Dmnl

(35) Outsource Quality=1

Units: Dmnl

(36) Outsourcing Fraction=1

Units: Dmnl

(37) Perceived Fraction Completed=MIN(1,ZIDZ(Work Believed to be Done, Task Work))

Units: Dmnl 
(38) Potential Completion Rate=Staff Level*Productivity

Units: Task/Day

(39) Productivity=(New Staff*New Staff Productivity+Experienced Staff Available For

Work*Normal Productivity)/(New Staff+Experienced Staff Available For Work)

Units: Task/people/Day

(40) Project Finished=IF THEN ELSE(Scheduled Completion Date+Minimum Time to

Finish Work-Time $<=0,1,0$ )

Units: Dmnl

(41) Quality=Quality Switch * Normal Quality * Effect of Prior Work on Quality + (1 -Quality Switch) * Normal

Quality

Units: Dmnl

(42) Quality Switch=1

Units: Dmnl [0,1]

(43) Rate of Doing Work=Rework Generation Rate+Work Accomplished Rate

Units: Task/Day

(44) Rework Discovery Rate=Undiscovered Rework/Time to Discover Rework

Units: Task/Day

(45) Rework Generation Rate=IF THEN ELSE(Project Finished, 0 , Total Task Accomplishment Rate*(1-Quality) )

Units: Task/Day

(46) Rework Switch=1

Units: Dmnl [0,1]

(47) SAVEPER = TIME STEP

Units: Day [0,?]

(48) Scheduled Completion Date= Table for Scheduled Completion Date(Time)

Units: Day

(49) Staff Getting Experience Rate=MAX(0, New Staff/Time to Gain Experience)

Units: people/Day

(50) Staff Hired Rate=MAX(0, (Extra Staff Needed/Hiring Delay)*Switch for Hiring)

Units: people/Day

(51) Staff Leaving Rate=Excess Experience Staff*"Weight on Progress-Based Estimate"* "Transfer/Firing Delay"

Units: people/Day

(52) Staff Level=MAX(0, Experienced Staff+New Staff)

Units: people

(53) Staff Level Required= Estimated Effort to Complete Based on Progress/Time Remaining

Units: people

(54) Switch for Hiring=1

Units: Dmnl $[0,1]$

(55) Switch for Productivity=1

Units: Dmnl $[0,1]$

(56) Table for Changed Work((0,0)-(70,10)],(0,0),(49.999,0),(50,10),(70,10))

Units: Task

(57) Table for Effect of Prior Work on Quality([(0,0.1)-(1,1)],(0,0.1),(0.1,0.25),(0.2,0.35),

$(0.3,0.45),(0.4,0.55),(0.5,0.675),(0.6,0.775),(0.7,0.85),(0.8,0.95),(0.9,0.99),(1,1))$

Units: Dmnl

(58) Table for Effect of Work Progress([(0,1)-1,0.05)],(0,1),(0.1,1),(0.2,1),(0.3,1),(0.4,1),(0.5,1),

$(0.6,0.95),(0.7,0.8),(0.8,0.45),(0.9,0.2),(1,0.05))$

Units: Dmnl

(59) Table for Scheduled Completion Date([(0,60)-(70,70)],(0,60),(49.999,60),(50,70),(70,70))

Units: Day

(60) "Table for Weight on Progress-Based Estimate"([(0,0)-(1,1)],(0,0),(0.1,0),(0.2,0),(0.3,0.1),

$(0.4,0.25),(0.5,0.5),(0.6,0.75),(0.7,0.9),(0.8,1),(0.9,1),(1,1))$

Units: Dmnl

(61) Task Work=Initial Task Work+Changed Work

Units: Task

(62) Time Remaining=MAX(Minimum Time to Finish Work, Scheduled Completion Date-Time)

Units: Day 
(63) TIME STEP $=0.5$

Units: Day [0,?]

(64) Time to Discover Rework=Rework Switch * Normal Time to Discover Rework*Effect of Work Progress + $(1$ Rework Switch) * Normal Time to Discover Rework

Units: Day

(65) Time to Gain Experience=5

Units: Day

(66) Total Task Accomplishment Rate=MIN(Max Completion Rate, Potential Completion Rate )

Units: Task/Day

(67) "Transfer/Firing Delay"=0.0083

Units: 1/Day

(68) Undiscovered Rework= INTEG (Rework Generation Rate-Rework Discovery Rate,0)

Units: Task

(69) "Weight on Progress-Based Estimate"="Table for Weight on Progress-Based Estimate" (Perceived Fraction

Completed)

Units: Dmnl

(70) Work Accomplished Rate = IF THEN ELSE(Project Finished, 0, Total Task Accomplishment Rate*Quality)

Units: Task/Day

(71) Work Believed to be Done=Undiscovered Rework+Work Done

Units: Task

(72) Work Done= INTEG (Work Accomplished Rate,0)

Units: Task

(73) Work to Do= INTEG (Rework Discovery Rate-Rework Generation Rate-Work Accomplished Rate+Changed Work /Min Time to Perform Task,Task Work)

Units: Task 